\title{
The cardiac magnetic resonance myocardial perfusion reserve index in the assessment of the revascularised left anterior descending artery
} Joyce L Wong*1, R Andrew Archbold ${ }^{2}$, Redha Boubertakh ${ }^{1}$, Anthony Mathur ${ }^{2}$, Pierre Monney ${ }^{1}$, Saidi Mohiddin ${ }^{1}$, Mark Westwood ${ }^{1}$ and L Ceri Davies ${ }^{1}$

Address: ${ }^{1}$ CMR Dept, London Chest Hospital, Barts and the London NHS Trust, London, UK and ${ }^{2}$ London Chest Hospital, Barts and the London NHS Trust, London, UK

* Corresponding author

from I3th Annual SCMR Scientific Sessions

Phoenix, AZ, USA. $21-24$ January 2010

Published: 21 January 2010

Journal of Cardiovascular Magnetic Resonance 20 I0, I 2(SuppI I):PI I2 doi:I0.I I86/I532-429X-I2-SI-PI I2

This abstract is available from: http://jcmr-online.com/content/I2/SI/PII2

(C) 2010 Wong et al; licensee BioMed Central Ltd.

\section{Objectives}

Myocardial perfusion reserve (MPR) is the ratio of maximum hyperaemic to rest myocardial blood flow, quantified with contrast-enhanced cardiac magnetic resonance (CMR) T1-weighted dynamic imaging and signal intensity-time curves of first-pass contrast. The assessment of myocardial perfusion post bypass grafting may be confounded by reduced systolic function and scar. Using a 32channel cardiac coil array, we assessed the accuracy of the MPR index (MPRI) in the revascularised left anterior descending (LAD) artery.

\section{Methods}

Twenty-eight patients ( 11 females, age $65+/-10$ years) were imaged on a 1.5 Tesla MR Scanner (Philips Achieva, Best, Netherlands) within 12 months of cardiac catheterisation demonstrating patency of left internal mammary (LIMA) grafts (14 patients), stented LAD arteries (5 patients), or the native LAD arteries ( 9 patients). Adenosine $(140 \mathrm{mcg} / \mathrm{kg} / \mathrm{min})$ was administered for 3 minutes to achieve maximum myocardial blood flow. Gadoterate meglumine contrast $(0.1 \mathrm{mmol} / \mathrm{kg}$, Dotarem, Guerbet, SA) was injected as a single bolus. Three short axis slices were acquired every heartbeat using a non-slice-selective saturation recovery perfusion sequence. A 20 minute resting period allowed partial washout of contrast agent between stress and rest. LAD territory perfusion was assessed in the basal and mid-ventricular anterior and anteroseptal segments; segments with late gadolinium enhancement were excluded. Quantitative myocardial perfusion reserve was derived from a Fermi constrained deconvolution model (CMR Tools, UK). Statistical analysis was performed using Graphpad Prism, USA.

\section{Results}

Our patient population with unobstructed LIMAs had significantly lower MPRIs than patients with unobstructed native LADs (median MPRI of 1.8 vs 2.42 , Kruskall-Wallis test with Dunn's multiple comparisons test, $\mathrm{p}<0.05$ ). No difference was seen with patent stented LADs. No difference was seen during stress in the mean transit time (MTT) of the contrast bolus during stress between patients with unobstructed LIMAs and native arteries. No difference in MPRI also was seen between the basal and mid-ventricular slices in the patients with unobstructed LIMAs.

\section{Conclusion}

Myocardial perfusion reserve indices were significantly reduced in patent LIMA grafts when compared to unobstructed native LAD arteries (normal ranges 2.5-5). Given the different arterial bed origin and longer course of the 
LIMA, further optimisation of quantitative assessment of perfusion post-revascularisation may prove useful.

Publish with Bio Med Central and every scientist can read your work free of charge

"BioMed Central will be the most significant development for disseminating the results of biomedical research in our lifetime. " Sir Paul Nurse, Cancer Research UK

Your research papers will be:

- available free of charge to the entire biomedical community

- peer reviewed and published immediately upon acceptance

- cited in PubMed and archived on PubMed Central

- yours - you keep the copyright

Submit your manuscript here:

http://www.biomedcentral.com/info/publishing_adv.asp 